\title{
Genetic Sequence Start Location
}

National Cancer Institute

\section{Source}

National Cancer Institute. Genetic Sequence Start Location. NCI Thesaurus. Code C135488.

The determination of the location on a nucleotide sequence that is considered to be the beginning of a genetic region of interest. 